\title{
Recruitment and Selection Process of Higher Education Sector and Its Impact on Organizational Outcomes
}

\author{
Ayesha Yaseen (MS Scholar) \\ Department of Management Sciences, The Islamia University of Bahawalpur \\ Email: Ayesha_ayesha12@hotmail.com
}

Doi:10.5296/ijhrs.v5i4.8822 URL: http://dx.doi.org/10.5296/ijhrs.v5i4.8822

\begin{abstract}
This research examines the recruitment and selection practices followed in Higher Education Institutions (HEIs). Today education is the corner stone of societal reforms in Pakistan and effective teachers are the backbone of educational reforms. HEIs need significant developmental measures and this paper will provide recommendations to improve the recruitment and selection process promoting the competent and talented teachers so that higher education sector can play its part in economic growth. The research methodology applied is exploratory. This research based on primary as well as secondary data collected from newly hired university lecturers, Managerial staff, internet and online journals and research papers. Data analysis has been done with the help of SPSS software. Research concluded that recruitment and selection process of HEIs adopt systematic system but there is a room for improvement. At times this process is influenced by political factors. This research will help in promoting active constructive researches on education sector as well as the fair and corruption less recruitment and selection processes of HEIs.
\end{abstract}

Keywords: Higher Education, recruitment practices, performance, selection tools 


\section{Macrothink}

\section{Introduction}

This research paper looks at the prevailing strategy and process of recruitment and selection of an employee in higher education sector. As it is the main task to attract, hire and retain the competent employees to ensure enhanced and productive organizational outcomes.

\section{Source of information}

Information is gathered from several sources meeting with HR manager of a university. Asking interview questions and by the questionnaire.

\section{Scope of the paper}

This paper highlights the strategy used for recruitment and selection its implementation, step by step processes and usage of these steps in order to gain competitive advantage and greater organizational outcomes. It will be a step forward towards the development of the Higher education sector in Pakistan.

\section{Purpose of the study}

Nowadays it's very important for an organization to compete well with competent personnel having right people at right time at right place. Organizations are now well aware of the importance of human resource management so the human resource management process starts with recruiting competent and optimum people at right time at right place. This process plays a vital role in the productivity of an organization. Competent employees can give a tough competition to the competitors so recruitment and selection of an employee needs to be handled with a healthy constructive and productive strategy, implementation and all steps that are used to implement the organization's recruitment and selection process.

\section{Objectives}

- To analyze common steps that organizations use to recruit and select employees.

- To determine how the recruitment and selection practices can be made better in G.C University.

\section{Literature review}

This research article investigates the strategy of recruitment and selection process currently prevailing in higher education sector and all the steps in the process that helps in implementing recruitment and selection strategy.

\section{Recruitment}

Recruitment is basically attracting and finding competent pool of candidates according to the requirements of the job or key position. Recruitment is the first part of the process of filling the vacancies; it includes following things:

- Identification of the vacancies

- Checking out sources of suitable candidates 
- Contacting with potential Employees

All steps implemented in order to find capable employees or the attraction of applications, form suitable applicantsCastetter (1992) suggested that, as competition is increasing a planed extensive program of hiring qualified talented employees should be introduced to conduct the work of educational system that should be directed towards hiring and retaining competent and motivated employee on every key position as it plays a significant role in an organization's effectiveness. In this way recruitment method help us to find capable candidates.

\subsection{The aims of recruiting:}

The basic aims of recruitment are:

- To create pool of suitable candidates for empty positions.

- To use a fair method.

- To conform that all recruitment activities are aligned to company's objectives and aims.

- To perform recruitment activities in an efficient and cost effective path.

\subsubsection{Recruitment Procedures:}

An organization must see its future staffing needs, job specification and a vacant space to be filled before attracting and contacting with candidates organization should identify best and most effective recruitment method.

Certain recruiting procedures produce the best suitable candidates according to the requirements for a particular job vacancy (Anderson, 1988; Castallo et al., 1992; Castetter, 1992; Herman, 1994). Before any link with applicants, human resource planning must check out current and future staffing needs and must identify the optimum number of employees. A job vacancy is analyzed to examine what the actual job descriptions are and what method of recruitment will be most effective in order to recruit most suitable candidate. There are some casual ways of recruiting, including internal recruitment, and findings referrals, linkages employment agencies, advertising requirements with college and university placement services, advertising in newspapers or internet and in the publications of professional organizations, following up on spontaneous or unwelcome forms and social linkage organizations that promote the interests of minority groups (Rebore, 1982, pp. 83-4). Most organizations have two types of candidates to select from which to recruit, outsiders or companies own employees. If there are enough qualified candidates internally as it motivates other employees, external recruitment may not be needed.

\subsubsection{Attracting practices:}

In the business world, as competition is increasing and world is a global village now the internet media advertising and specifically the newspaper advertisement plays a significant role in the recruitment process. Boudreau and Rynes (1985) believed that most cheap cost effective medium of advertising is newspaper advertising and playing a vital role in the 


\section{Macrothink}

attracting and hiring process.

\subsubsection{Methods of recruitment:}

There are two methods of recruitment internal and external recruitment.

\section{a) Internal Recruitment:}

Herman (1994) suggested three ways to hire from within the organization. First approach is that manager presents the transfer plan of the particular person to the supervisor to whom that particular employee is currently reporting if both parties agree to the transfer plan the promotion is made for specific key position. This approach is not much appreciated as it is considered to be unfair and biased by other candidates those who are seeking leadership opportunities. Job posting and searching employer's skill inventories and succession plans are the two other ways Herman suggested to recruit internally.

\section{b) Skill inventory:}

Employees already working in the organization they can be promoted by checking their personal records, application forms and performance. If they have not been given job according to their skills or education level they can be promoted according to their potential and capabilities. Training can also be provided to currently working employees to get promotion to upgraded leadership positions those who have specific skills and potential can be approached for career advancement.

\section{c) Job posting:}

Job posting means listing all the job specifications and attributes like qualifications, supervisor, schedule, and salary. It facilitates the transfer and promotion of qualified candidates within the organization.

\section{d) Informal search:}

The manager of the department and human resource manager together discuss the vacancies and employees that can be promoted or considered suitable for higher leadership positions. They can take interview of those employees and make a job offer to the most appropriate employee who is really interested and deserving.

\section{e) External recruitment:}

Many vacancies are filled from outsiders. Even when an company own candidates if transferred or promoted elsewhere in the company there comes a vacant position, which should be filled externally.

\section{f) Advertising:}

The most popular method of recruitment is giving advertisement thus creating a pool of qualified. 
g) Private/employment agency:

Organizations, which are working as public figure for supplying employers with candidates for jobs, are of two main types.

1) Office staff employment agencies

2) Selection agencies for senior staff

\section{Office staff employment agencies:}

Office staff employment agencies usually provide clerical, typing and machine operator employees and take fee from the organization.

\section{Selection agencies for senior staff:}

Selection agencies for senior staff, which usually deals with managerial and senior post job vacancies. The agency analyzes the job, prepares job and specifications and attributes. Give advertisement and sends out application form and interviews selected candidates, sometimes posting them. The final screening is done by employer with the help of a list of candidates and brief about employee's education and future position he acquired

\section{h) Unsolicited applications:}

Organization receives many applications that from surroundings. Employer often find them satisfactory for hourly paid blue color worker and clerical personnel. Technical, professional, and administrative potential personnel will apply for job by sending their resume to the personnel office even when the firms have not advertise any job opening or vacancy.

\section{i) Job Fairs:}

Job fairs are organized by graduating institutions where companies are invited to arrange their stalls and interview the potential candidates it's more like talent hunt program.

\section{j) Employee referrals:}

Currently working employees suggest candidates to the organization. Those are referrals seen less likely to leave the organization in the first year but they might leave in first year if the working condition or environment of the firm is not satisfactory and employee gives the realistic job preview to the referral.

\section{k) Professional associations:}

Engineers, physicians, professors, and lawyers are usually member of professional associations. These associations work as a platform giving them an open environment and opportunity to share thoughts and seek employment opportunities. Which organization seeks for their own employees who are members of professional associations to recruit using this method? 


\subsubsection{AIDA model:}

Advertisements are required to promote attention, interest, desire, and action (AIDA). Redman and Mathews (1992) described the AIDA model.

A - Attention - suggests using a large, multi-shades if affordable with identifiable company logo or noticeable name which catches eyes. The job title should be highlighted.

I - Interest - generate interest through the job and advertisement by ensuring the potential candidates that the job offer should must be considered more over provide realistic job preview and the potential candidate has the necessary abilities to apply for the job by stating clear job title, location, salary on the top, experience, qualifications, and personal attributes below.

D - Desire - means stating the nature of employment, giving a clear image of the organization, stating the entire rewards package and communicating job hardships and opportunities.

A - Action - refers to the final stage of the advertisement which will clearly stimulate them to act or do apply for the key position.

Because of a large number of job applicants, school boards have paid little attention to this model.

\subsubsection{Difficulties with Recruitment:}

An organization has to see different issues while recruiting an applicant. Organization has to make a rational decision while recruiting and selecting that there shouldn $\mathrm{t}$ be any biasness or corruption in the strategy or in the process because it will damage the reputation of the firm.

According to the laws and various civil rights legislation in united states, equal employment opportunity should be provided to all without any discrimination of race, age, deficiency, military jobs , complexion, religion, sex, pregnancy, and national origin language (Rebore, 1982, p. 72). In Canada, the Canadian Charter of Rights and Freedoms and the Saskatchewan Human Rights Code insists equality rights in Saskatchewan and prohibit discrimination on the basis of factors like race, color, religion, age, sex, or disability (STF, 1987, p. 1).

Higher education sector, universities can eliminate discrimination by devising healthy, planned and systematic recruitment policy and process and it should be written.

\subsubsection{Who is Responsible for Recruitment?}

Human resource staff is assigned for recruitment and selection process.

Recruitment can be managed by a group (panel) or by a single individual. The board of education should be the first mover in developing the recruitment process or strategy; once the strategy is made, to perform duty of recruitment should be given to a chief officer, or single in charge of the personnel function (Anderson, 1988; Caldwell \&Tymko, 1990; Castallo et al., 1992; Castetter, 1992; Genck\&Klingenberg, 1980; Musella\& Lawton, 1986).

Castallo et al. (1992) agreed with Castetter and suggested that the primary role of the board 
of education was to develop recruitment and selection strategy or policy, while the role of administration was to implement those policies. Castetter suggested that these strategy or policy should be documented so that it gives clear guidance.

\section{The recruitment of good teachers: A challenge}

While recruiting teachers institutions wish to attract candidates who are well prepared, effective and who will remain in the teaching profession for long time and innovative." (Darling Hammond, Berry, Haselkorn and Fideler, 1999).

Hirsch (2001) offers a board of solutions to progress the value and quality of teachers recruited at higher educational level ended up with a suggestion of salary increment. However there is no guarantee that increasing salary will improve teaching quality of recruited teachers. More over Hanushek, Kain, Rivkin (1999), who compared the effectiveness of teachers from faculty of secondary schools in Texas, so that link between teacher ,student and salary must be found performance was not clear. "Important policy steps rest on the relationship between teacher salaries and the quality of 18teachers, but proof was not up to mark." (Hanushek, Kain, Rivkin, 1999). They show that teachers ${ }^{\text {ee }}$ salaries have only a "meek impact" both on teacher mobility and on student performance. A considerable relationship between student's success and salary existed for experienced teachers, but not for new hires (Hanushek, Kain, Rivkin, 1999).

\section{Communication skills:}

Shulman (1993) identifies communication skills and better delivery of knowledge as a key element of teaching. He asserts that to move towards a scholarship of teaching, it is very important that teachers active members of communities regarding communication and calculation.

\section{Experience matters:}

Chalmers (2007) pointed out that experience matters a lot: More than 400 empirical studies show that years of experience in teaching and specific teaching qualifications are positively correlated to better student performance (Greenwald, Hedges \&Laine, 1996).

\section{Selection}

End result of a constructive recruitment is having suitable competent candidates from the pool of people. Next step is selecting the most productive and suitable person according to the requirements of the job vacancy it can be done by assessing the candidates by various tools or measures and making a rational choice or decision followed by an offer of employment.

The ultimate goal of the selection is usually choosing the best person for the job. Selector predicts performance of the candidate on the job, but they also need to ensure that the candidate is best suitable and acceptable he is not instable will not leave the firm in a short period of time.

The basic aim of selection as stated by Castetter (1992) is to fill the vacant vacancies with 
personnel who meet the job related competencies, self-motivated and directed or inclined towards success, consistent, efficient towards goals, system and organization, contribute well and quick learner directed towards self-development.

\subsection{Aims and objectives of the selection process:}

- Gather as much relevant information to analyze the facts.

- Organize and evaluate the information to make the rational choice.

- Assess each candidates in order to choose the best person for the job

- Forecast performance of a candidate on the job and its compatibility with the firm.

- Provide knowledge to applicants so that they can judge whether or not they are ready to accept an offer of employment considering the hardships and opportunities.

\section{Factors to be considered while selecting:}

- Size of the organization

- Number of people to be hired

- Nature of the job to be filled

- An outside pressure or influence

- Pinpoint criteria of an organization selection process

\subsubsection{Selection Process:}

There are various steps normally followed in processing applicant for a job. Following are the main steps, which more or less followed in many organizations.

\section{Interview structure:}

Herman (1994) suggested that there should be a structure and a valid reason to ask questions in an interview and proper systematic method and tools to evaluate answers of those questions because it can help in forecasting applicant's performance on the job.

Interviewing an applicant requires training and skills because you have to analyze examine the applicant whether he is suitable for the job or not, whether he will contribute well in the profit maximization or not.

Designing application and interview questions is both an art and a science. The art is determining what questions will help you in identifying the competency capabilities of an applicant. The science is in determining whether this applicant will enhance the productivity of an organization or not. (Herman, 1994, p. 87).

\section{Problems with interview:}

Interviewers should be trained, make rational decisions and logical while asking questions and investigating potential employees ${ }^{e e}$ behavior on the job and forecasting his performance 


\section{Macrothink}

and contribution towards the company's welfare. Anything fails to be fair and rational will be problematic and an interview of few minutes cannot decide all the facts and figures clearly and result of an interview is based on forecasting performance and predicting future is always uncertain. Yet it is not authentic in predicting job success some candidates can better sell their skills some are not good in delivering or in communication.

According to authors: (Anderson, 1988; Castetter, 1992; Gibney, 1987; Herman, 1994) these are the problems with an interview:

- Lack of training by the interviewers

- Unstructured interview

- Disagreement on questions to be asked

- Disagreement on topics to cover

- Different perspectives

- No valid weight age system given to the answers

- Risk of asking illegal questions

Herman gave seventeen reasons to prove that interviews are invalid, unreliable and potentially illegal. She also explained that sometime interviewers become over confident, wrongly compare like apples with oranges, and dostereotyping (pp. 116-120). Though much emphasis is placed on the interview, research also proved that the outcome of an interview could be misleading and biased. (Broussard et al., 1989; Castetter, 1992; Musella\& Lawton, 1986).

\section{Structured Style Interview:}

Structured interview is already structured predefined set of questions are asked from the applicant for the same job. (Herman, 1994, p. 122).

\section{Components of a structured style interview:}

It includes following:

(a) job requirements, (b) situational questions, (c) job related questions, (d) job simulation questions, (e) worker necessary queries, (f)validity assessment , (g)checking of responses, (h) multiple raters (colleague group, interview team (i) short notes taken by interviewers, $(\mathrm{j})$ imitative procedures, $(\mathrm{k})$ consistently applied to each applicant, and (1) standardized questions (Herman, 1994, pp. 122-3).

Structured questions and weighted interview process end up with greater chance of selecting an appropriate leader (Castetter, 1992; Herman, 1994; Marshall \& Grey, 1992; Musella\& Lawton, 1986; Stout, 1973). 


\section{Macrothink \\ International Journal of Human Resource Studies \\ ISSN 2162-3058 \\ 2015, Vol. 5, No. 4}

\section{Unstructured style interview:}

Unstructured interview is casual and unrehearsed followed by open ended questions. They depend on free flowing conversation as communication skills and exchange is much more important than the questions being asked which tends to focus on your personal attributes.

\section{References:}

Employer check references by verifying his past records, effectiveness and critical information that eliminates employer liability or negligence. However this part is ignored in many screening processes (Herman, 1994). Herman thought the telephone and in-person references are very affective regarding job applicant. The lack of attention to the reference investigation is due to the fact that candidate must have given favorable references because former employers will also give harmless remarks due to the fear of legal problems (Herman, 1994, p. 146)

\section{Induction and probation:}

If a potential employee's final selection has been done then the induction and probation is the last step of the recruitment and selection. It accommodates the employee's specific needs. However in small organizations the owner makes the final decision of accepting or rejecting the candidates.

\section{Orientation:}

After inducting a new employee to the organization he is formally introduced with the firm and its culture. An effective orientation program supports your recruitment efforts. Research shows that an effective orientation will increases productivity and boosts moral and reduces staff turnover and absenteeism and will help in developing positive working relationship with your employees. Conducting a well-planned and systematic orientation program for new hires pays many dividends for both you and your new staff.

\section{Timing of orientation:}

Orientation programs timing can be of an hour or two to several days in length.

\section{Components of orientation:}

There are purely following components to an orientation program:

- Casual introduction into the company, its culture, norms, vision and methods.

- Departmental or job-specific orientation was when the workers started their jobs ${ }^{\text {ec By }}$ "socializing everyone $\ldots$ in the culture and values that makes the organization unique," new employees are enabled to ,live the valuese and get identified as of their new company (Meister, 1998, unpaginated) 


\section{Macrothink \\ International Journal of Human Resource Studies \\ ISSN 2162-3058 2015, Vol. 5, No. 4}

\section{Research design: Descriptive research}

This research paper is based on descriptive research because aim is to find and understand the process of recruitment and selection in higher education and giving suggestions for improvement and its impact on the organizational outcomes.

\section{Sampling technique:-convenient Sampling}

Convenient sampling is a form of sampling based on the convenience of the researcher.

\section{Target population and Sample size}

The target population was the employees of the HR department of G.C University Faisalabad.

A sample size of 60 employees of G.C University Faisalabad has been taken.

\section{Findings:}

- GCU has structured system for selection and recruitment of employees.

\section{Figure 1.1}

\section{Structured system:}

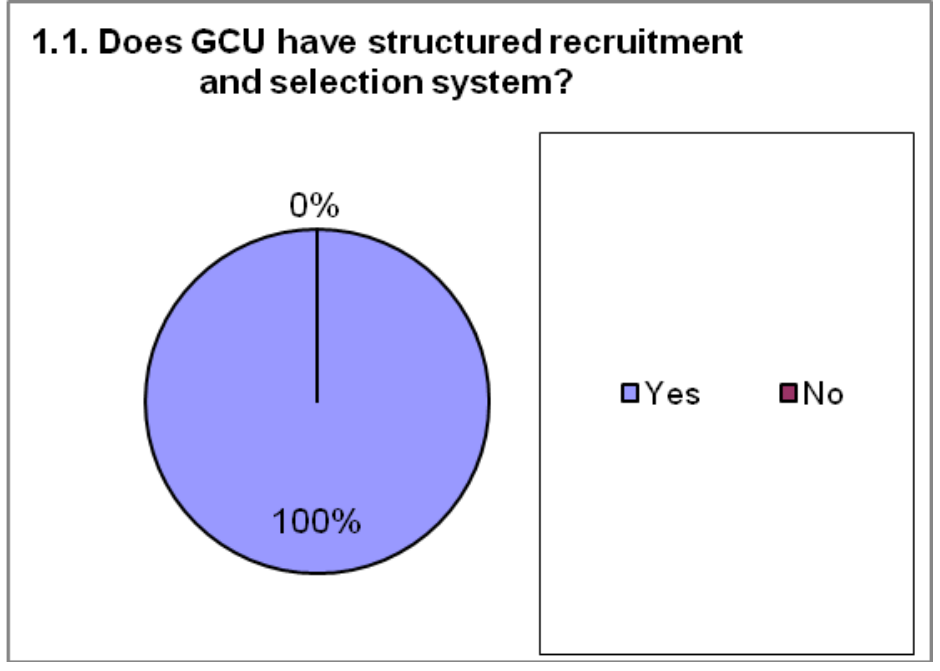

According to employees in GCU the steps involves are,

1. Advertisement in news paper

2. Applications

3. Dispatch of call letters

4. Interview 
5. Selection board

6. Syndicate

7. Notification

8. Joining

Figure 1.2:

Effectiveness of recruitment and selection process

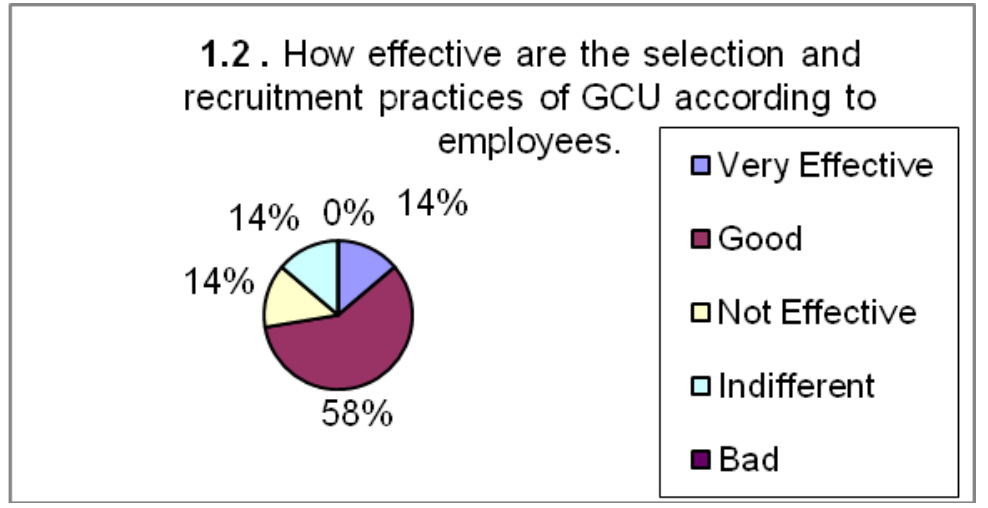

- GCU have good selection and recruitment system but yet there is room of improvement. As most of employees comment that selection and recruitment at GCU is partially fair but at times political influence try to overrun the fair system.

- For most of employees the fair selection and recruitment is motivating as they thought that if they are selected at merit without any reference they would be loyal to their job and would work hard for the sake of GCU. While some thinks that they are selected so now there is no role of selection and recruitment for further job.

\section{Figure 1.3:}

Selection and recruitment and its impact on motivation and performance:

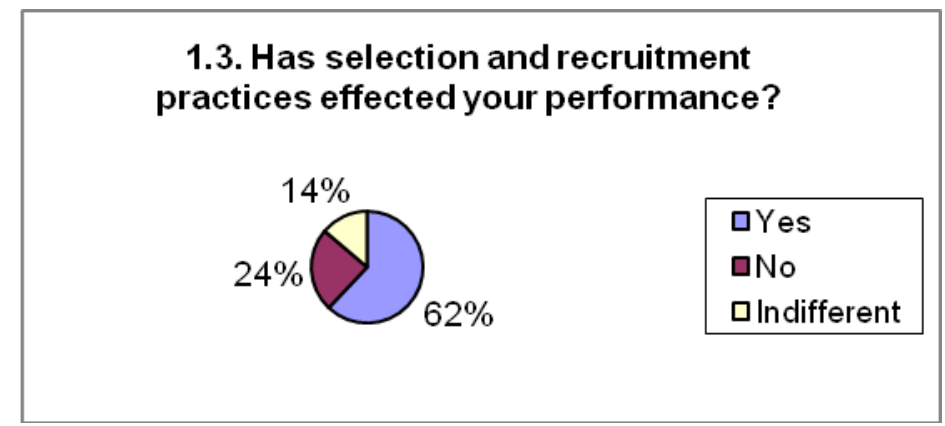


- When vacancies occur existing employees are consider first which motivate employees to work hard for their career development.

\section{Figure 1.4:}

\section{Internal recruitment:}

\subsection{When vacancies occur are existing employees considered?}
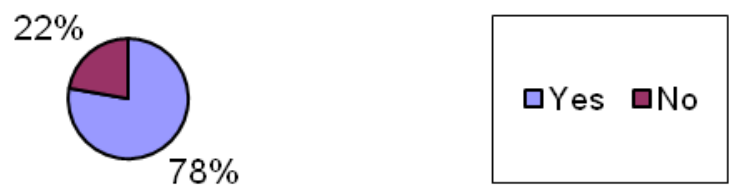

- According to HR managers they consult their selection and recruitment system as best and it led to the employment of competent staff and management does not circumvent the formal system. And there is equal opportunity for both male and females strictly on merit.

Figure 1.5:

Recruitment and Selection tools an aid to hire competent staff:

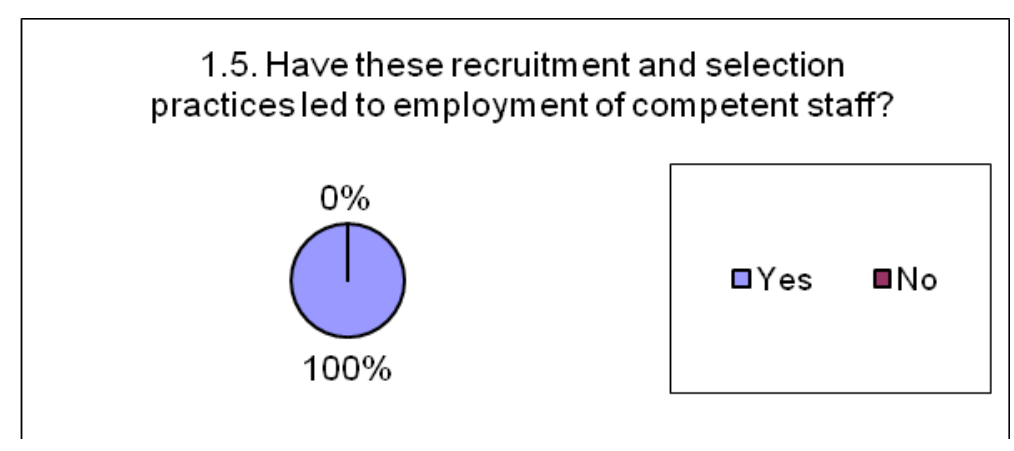

\section{Conclusion:}

Researchers in this research are of the view that GCU needs revision of its set up of selection and recruitment starting from job advertisement to the hiring of employees. As advertisements are given in newspaper while it could be improved by giving advertisement in other medium like internet etc that would increase the pool of candidates. Organization needs to remind itself the crucial role of HR in employee's selection and recruitment. 


\section{Macrothink}

International Journal of Human Resource Studies

ISSN 2162-3058

2015, Vol. 5, No. 4

Although GCU have effective selection and recruitment system but it can be improved as well. As HR officers consider it as the one of best system and want and not willing to change or modify it while it has capacity for modifications to be made.

Selection and recruitment system in GCU should be confidential and before time the names of selected people should not be announce so that political agents may not wrongly force to select incompetent candidates.

\section{Recommendations}

- The organization should maintain a proper formal written recruitment and selection process.

- The organization should advertise for high and average skills positions in the metropolitan daily newspaper and internet.

- The organization adopts structured interviews for all positions classed as high and average skilled.

- The organization should use comfortable lounge-type seating area and a coffee table to be used to take interviews in the interview room.

- The organization should adopt and flourishes an employee orientation program.

- The organization should take care of that the orientation program is held with new employees on their very first day, where it must be held on first day or may than in initial week.

- All employees should be aware of selection and recruitment policy, criteria and tools.

- Selection and recruitment should be free of political influence and personal biasness.

- Organization should focus more on qualified as well as experienced candidates.

- Organization should avoid political influence and personal biasness for improved and effective system

\section{References:}

- Anderson, M. E. (1988). Hiring capable principals: How school districts recruit, groom, and select the best candidates [Monograph]. Oregon School Study Council, 31 (9), 1-37.

- Boudreau, J. W., \&Rynes, S. L. (1985). Role of recruitment in staffing utility analysis. Journal of Applied Psychology, 70 (2), 354-366.

- Broussard, R. L., Arceneaux, C. J., \&Boutte, C. B. (1989). A study of the job requirements and selection process for elementary principals and assistant principals in selected public and private school systems. University of Southwestern Louisiana, Lafayette, LA. 


\section{Macrothink}

International Journal of Human Resource Studies

ISSN 2162-3058

2015, Vol. 5, No. 4

- Caldwell, B. J., \&Tymko, J. L. (1990). Policy making for education: A guidebook for boards of education (2nd Ed.). Alberta School Trustees Association.

- Castallo, R. T. (ed.), Fletcher, M. R., Rossetti, A. D., \&Sekowski, R. W. (1992). School personnel administration: A practitioner's guide. Boston: Allyn\& Bacon.

- Castetter, W. B. (1992). The personnel function in educational administration (5t ed.). New York: Macmillan.

- Chalmers, D. (2007) A review of Australian and international quality systems and indicators of learning and teaching, Augustesearch, 66, 361-396.

- Darling-Hammond, L., Berry, B.T., Haselkorn, D., \&Fideler, E. (1999). Teacher recruitment, selection, and induction: Policy influences on the supply and quality of the teachers. In L. Darling-Hammond \& G. Sykes (Eds.), Teaching as the learning profession: Handbook of policy and practice (pp. 183-232). San Francisco, CA: Jossey-Bass Publishers.

- Genck, F. H., \&Klingenberg, A. J. (1980). The school boardps responsibility: Effective schools through effective management. Springfield, IL: Illinois Association of School Boards.

- Gibney, J. (1987). An interviewer's handbook. S.S.T.A. Research Center, Report No. 148.

- Greenwald, R., Hedges, L.V., \&Laine, R.D. (1996). The effect of school resources on student achievement. Review of Educational Research 66(3), 361-396.

- Hanushek E., Kain J., Rivkin, S. (1999), “Do higher salaries buy better teachers?”, NBER Working Paper

- Herman, S. (1994). Hiring right. Thousand Oaks, CA: Sage.

- Hirsch, E., Koppich, J., \& Knapp, M. (2001). Revisiting what states are doing to improve the quality of teaching: An update on patterns and trends. Seattle, Washington: Center for the Study of Teaching and Policy, University of Washington. Retrieved $\quad$ March 31, 2005 from http://depts.washington.edu/ctpmail/PDFs/States-HKK-02-2001.pdf

- Hirsch, E. (2001), “Teacher Recruitment; Staffing Classrooms with Quality Teachers”, State Higher Education Executive Officers

- Human Resource Management (5th Edition) Garry Dazzler.

- Introducing Human Resource Management Margaret Foot \& Caroline Hook LONGMAN London \& New York (ARTICLE'S REFERENCES)

- Loder, R. A. (1982). The selection of school principals in Saskatchewan. Unpublished masterps thesis, University of Saskatchewan, Saskatoon, SK. 
- Marshall, C., \& Grey, R. (1992). Legal rights of women seeking administrative positions in local school districts. In C. Marshall (ed.), Women as School Administrators (pp. 81-87). Indianapolis, IN: Phi Delta Kappa.

- McGraw-Hill Goldhaber, D.D., Brewer, D.J. and Anderson, D.J. (1999). "A Three-Way Error Components Analysis of Educational Productivity." Education Economics, 7 (3), 199-208.

Hanushek, E.A. (1992). "The Trade-Off between Child Quantity and Quality." Journal of Political Economy, 100 (1), 84-117.

- Meister, J. (1998). Corporate universities: Lessons in building a world-class work force. New York:

- Musella, D., \& Lawton, S. (1986). Selection and promotion procedures in Ontario school boards. Professionalism in schools series. Toronto: Queenps Printer for Ontario.National Association of Elementary School Principals National Education Association. (1970). The assistant principalship in public elementary schools - 1969. A research study. U.S.A. Parents selecting principals. (1985). the Canadian School Executive, 5 (4), 29-30.

- Rebore, R. W. (1982). Personnel administration in education: A management approach. Englewood Cliffs, NJ: Prentice-Hall.

- Recruiting in china Author: Stephene Overman Issue: March 2001. www.findarticles.com

- Redman, T., \& Mathews, B. P. (1992). Advertising for effective managerial recruitment. Journal of General Management, 18 (2). John W.Boudreau BPI, IRWIN Company.

- Rivkin, S.G., Hanushek, E.A. and Kain, J.F. (1998). Teachers, Schools and Academic Achievement. (Working Paper 6691). Cambridge, MA: National Bureau of Economic Research.

- Sanders, W. and Rivers, J. (1996). Cumulative and Residual Effects of Teachers on Future Student Academic Achievement. Knoxville, TN: University of Tennessee, Value-Added Research and Assessment Center.

- Shulman, L.S. (1993), Teaching as community property, Change, Nov-Dec, Vol.25, No.5

- The importance of cost per hire (Analysis of recruitment cost) Author: Barbara Davison Issue: Jan 2001

- What's up with internet recruiting Author: WORK FORCE Advertising Department Issue: March 2000.

\section{Copyright Disclaimer}

Copyright reserved by the author(s). 